\title{
PERHITUNGAN BIAYA KETERSEDIAN OUTBOARD AFT FLAP PADA MAINTENANCE PESAWAT B737-800NG
}

\author{
Siti Azizah Latifa Dinar(1), Tri Susilo(2), Freddy Franciscus ${ }^{(3)}$ \\ Prodi Teknik Penerbangan, Fakultas Teknologi Kedirgantaraan, \\ Universitas Dirgantara Marsekal Suryadarma \\ Komplek Bandara Halim Perdanakusuma, Jakarta 13610, Indonesia
}

\begin{abstract}
Abstrak - Penelitian ini bertujuan mengetahui perencanaan biaya ketersediaan outboard aft flap. Dalam pemecahan permasalahan penelitian ini dilakukan dengan mengunakan aplikasi SWIFT dalam mengantisipasi keterlambatan pesawat dalam kondisi return to service, serta perhitungan estimasi cost yang timbul. Jika maskapai PT. XXX tidak melakukan loan spare part, maka harus mengeluarkan biaya perbaikan sebesar US\$2.804,46, namun dengan kehilangan total daily revenue sebesar US\$ $245.552,18$. Sedangkan, jika maskapai PT. XXX menggunakan loan part, maka hanya mengeluarkan total biaya sebesar US\$ 5.227,31 tanpa kehilangan daily revenue.
\end{abstract}

Kata Kunci: Outboard aft flap, B737-800NG, Daily revenue.

\begin{abstract}
This research aims to determine the effect of aft flap spare outboard on revenue of the company. In solving this problem, data collection and data analysis were carried out on the planning of the spare outboard aft flap for Garuda Indonesia B737-800 NG aircraft using the SWIFT application of PT. GMF Aeroasia in order to anticipate delays in return to service and cost calculations to prevent loss of daily revenue. If PT.XXX airline does not carry out a loan spare part, it must incur a repair cost of US\$ 2,804.46 and a total loss of daily revenue as US\$245,552.18. Meanwhile, if PT. XXX airline uses a loan part, only pay the fee of $\$ 5,227.31$ without losing daily revenue.
\end{abstract}

Keywords: Outboard aft flap, B737-800NG, Daily Revenue. 


\section{Pendahuluan}

Sebuah perusahaan dituntut untuk memiliki daya saing yang kuat di tengah ketatnya persaingan di era globalisasi saat ini. Dalam rangka memenangkan persaingan sebuah perusahaan dituntut untuk memberikan tingkat pelayanan yang baik sehingga memberikan tingkat kepuasan yang baik pula bagi para customer. Hal tersebut tentu sejalan dengan tujuan dari sebuah perusahaan untuk mendapatkan keuntungan dengan cara memberikan kepuasan kepada para customer.

Perusahaan penyedia jasa yang sangat dibutuhkan saat ini salah satunya adalah perusahaan yang bergerak di bidang transportasi. Hal ini diakibatkan karena tingkat pertumbuhan penduduk dan ekonomi yang tinggi sehingga berdampak pada tingginya mobilitas penduduk.

Mobilitas penduduk yang tinggi itulah yang menjadikan perusahaan penyedia jasa transportasi sangat dibutuhkan. Kondisi geografis Indonesia yang merupakan negara kepulauan yang memiliki banyak pulau-pulau membutuhkan transportasi yang efektif dan efisien. Hal ini menjadikan penyedia jasa transportasi penerbangan salah satu jasa yang sangat dibutuhkan.

PT. XXX (nama perusahaan dirahasiakan) sebagai perusahaan penyedia jasa transportasi harus menjaga mutu pelayanannya yang berkualitas diantaranya ketepatan waktu terbang agar tidak delay yang mana salah satu faktor yang dapat mempengaruhi on time performance tersebut adalah penanganan teknik.

Penanganan teknik yang dilakukan guna mencegah atau memperbaiki kerusakan (damage) yang terjadi. Salah satu kerusakan repetitive yang sering terjadi pada pesawat yaitu outboard aft flap Boeing B737-800NG mengalami disbonding atau hilangnya daya adesi yang akan menyebabkan terpisahnya skin dengan honeycomb core, sehingga part tersebut harus dilakukan perbaikan atau repair.

Dengan latar belakang permasalahan di atas, dapat diketahui bahwa kegiatan penanganan teknik memiliki peranan penting untuk menghindari terjadinya delay sehingga dapat menurunkan daya saing suatu perusahaan jasa transportasi. Untuk itu, dalam penelitian ini mengetengahkan tema tentang Perencanaan Biaya Ketersediaan Outboard Aft Flap pada Maintenance Pesawat B737800NG.

\section{Metode Penelitian}

Pada penelitian ini, dilakukan pengumpulan data outboard aft flap disbond dalam kurun waktu terhitung pada 1 Januari 2019 hingga 31 Desember 2019. Kemudian, dalam prosesnya juga dilakukan penentuan part number yang paling banyak digunakan dan paling sering terjadi kerusakan disbond pada pesawat B737800NG milik PT. XXX.

Dalam proses penelitian, juga dilakukan pencarian harga dengan serviceable condition untuk outboard aft flap, yang kemudian dilakukan perhitungan harga material dan harga manhour dari perawatan yang akan dilakukan, serta perhitungan perhitungan losses cost bagi PT. XXX. Ketiganya dilakukan perbandingan atas biaya yang ditimbulkannya.

\section{Pembahasan}

\subsection{Analisa Pengadaan Spare Outboard Aft Flap}

Berdasarkan penarikan data dengan gunakan aplikasi SWIFT yang dimiliki oleh PT. XXX. Data outboard aft flap disbond diambil dalam periode waktu 1 Januari 2019 hingga 31 Desember 2019.

Dari hasil penarikan data, terdapat 98 data berisi deskripsi part, part number 113A3700-22 untuk outboard aft flap; 


\section{a. Perbaikan Outboard Aft Flap Due to Disbond}

Suatu dokumen pabrik telah menerangkan secara rinci bagaimana pengerjaan perbaikan suatu part. Dengan kata lain perbaikan dari outboard aft flap dijelaskan secara rinci pada Structure Repair Manual sesuai dengan tipe pesawat.

Hal yang pertama dilakukan adalah inspeksi atau General Visual Inspection (GVI). GVI adalah inspeksi yang dilakukan hanya dengan menggunakan anggota tubuh yaitu indera penglihatan mata, hanya dengan menemukan kerusakan dapat diketahui sesuai dengan yang tertera pada manual handbook.

Pemeriksaan visual dapat dilakukan di are interior atau exterior. Instalasi untuk mendeteksi kerusakan dan kegagalan. Tingkat inspeksi ini dibuat dari jarak menyentuh kecuali terdapat kendala lain. Sebuah cermin mungkin diperlukan untuk membantu meningkatkan akses visual ke semua permukaan yang terbuka di area inspeksi. ${ }^{[6]}$

Tingkat inspeksi ini dibuat dalam kondisi pencahayaan yang normal seperti siang hari, pencahayaan hanggar, senter atau lampu dan mungkin memerlukan pelepasan atau pembukaan panel akses atau pintu. Dudukan, tangga atau platform juga diperlukan untuk mencapai area yang sedang diperiksa. Hal ini dijelaskan secara terperinci pada Structure Repair Manual (SRM) di ATA chapter 51-0006 "General Structure Repair Definition".

Setelah dilakukan inspeksi sesuai dengan allowable damage pada dan diketahui terdapat kerusakan disbond, maka dilakukan perbaikan menurut SRM ATA Chapter 57-53-01.

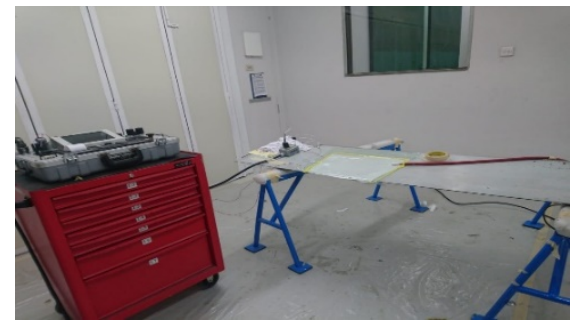

Gambar 3.1. Leading edge access panel removal

1. Melepas leading edge panel untuk akses perbaikan.

2. Perform permanent repair :

a. Cutting skin damage

b. Cut and remove the damaged skin and core, as necessary.

c. Prepare Doubler (Surface preparation): Make repair doubler and the repair skin from the same material and thickness as the initial skin. Make the repair doubler.

d. Apply adhesive

e. Replace the damage core if necessary.

f. Bonding

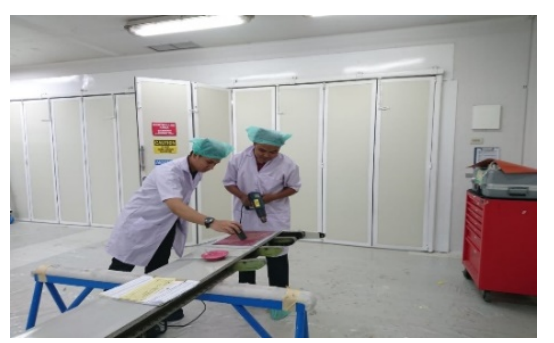

Gambar 4.2. Prepare doubler

3. Perform ultrasonic inspection after repair to ensure no disbond. ${ }^{[7]}$

4. Leading edge access panel installation

5. Apply aircraft exterior paint. ${ }^{[8]}$

b. Analisa Pengadaan Spare Outboard Aft Flap

Setelah diketahui part number dari outboard aft flap dilakukan pencarian source dari beberapa supplier yang menjual part tersebut dalam keadaan serviceable condition diperoleh:

Tabel 3.1. Outboard aft flap pricing

\begin{tabular}{|c|c|c|c|c|c|}
\hline Part Number & Alt PN & Condition* $^{*}$ & Certificate & Price & LTD \\
\hline 113 A3700-22. & 113 A3700-12 & SVC & FAA+EASA & $\$ 27,500 /$ EA & $\begin{array}{c}2 \\
\text { DAYS }\end{array}$ \\
\hline 113 A3700-22. & $113 A 3700-8$ & SVC & FAA+EASA & $\$ 13,500 / E A$ & $\begin{array}{c}4 \\
\text { DAYS }\end{array}$ \\
\hline \multicolumn{5}{|c}{ "SVC = Serviceable Condition }
\end{tabular}

Beda harga yang diperoleh tergantung alternate dari part number yang ditawarkan serta waktu pemesanan barang. Seperti yang 
tercantum pada Table di atas, harga outboard aft flap diketahui PN 113A700-22 dengan alternate PN 113A3700-12 kondisi serviceable seharga US\$27,500/ea pemesanan selama 2 hari, sedangkan dengan alternate part number 113A3700-8 kondisi serviceable didapatkan dengan harga US\$ 13,500/ea pemesanan selama 4 hari.

Kedua part number dapat digunakan, hanya saja beda waktu pemesanan mempengaruhi harga beli dari outboard aft flap. Jika harga loan outboard aft flap yang di tawarkan diketahui sebesar US\$ 1.000 per flight cycle maka:

Part number 113A3700-22 dengan alternate part number 113A3700-12 US\$27.500/ US $\$ 1.000=27,5$

Dibutuhkan 28 flight cycle untuk mengembalikan cost yang telah dikeluarkan.

Part number 113A3700-22 dengan alternate 113A3700-8 US\$ $13.500 /$ US $\$ 1.000=13,5$ Dibutuhkan 14 flight cycle untuk mengembalikan cost yang telah dikeluarkan.

c. Perhitungan harga manhour dan material repair

Berikut adalah harga yang harus dikeluarkan oleh maskapai PT. XXX untuk melakukan perbaikan outboard aft flap di shop, sesuai dengan kebutuhan material repair, dan harga ditentukan sebesar US $\$ 40$ per hour.

Tabel 3.2. Material for repair outboard aft flap

\begin{tabular}{|c|c|c|c|c|}
\hline DESCRIPTION & PART NUMBER & DESCRIPTION PART & QTY & PRICE (USD) \\
\hline \multirow{8}{*}{$\begin{array}{l}\text { OUTBOARD } \\
\text { AFT FLAP }\end{array}$} & BACB10GS06AKJP18 & BEARING-ROLLER & 1EA & $\$ 168.00$ \\
\hline & $113 A 3172-55$ & SEAL & $2 \mathrm{EA}$ & $\$ 231.00$ \\
\hline & 113A3172-13 & SEAL & 1EA & $\$ 94.50$ \\
\hline & BACB3OZE $3 K 4$ & SCREW & $15 \mathrm{EA}$ & $\$ \quad 157.50$ \\
\hline & AF163-2K-06 & $\begin{array}{l}\text { EPOXY ADHESIVE } \\
\text { FILM }\end{array}$ & $0,1 \mathrm{FT}$ & 94.82 \\
\hline & BR6747-1 & ADHESIVE PRIMER & $\begin{array}{l}0.008 \\
\text { GAL }\end{array}$ & 6.83 \\
\hline & AC-130-2 & SOL GEL & $\begin{array}{c}0.250 \\
E A\end{array}$ & 10.50 \\
\hline & AMS4049-020 & $\begin{array}{l}\text { AL-CLAD SHEET } 7075 \\
\text { T6 SIZE 0.020 } \\
\text { THICKNESS }\end{array}$ & $\begin{array}{l}0,005 \\
\mathrm{SH}\end{array}$ & 1.31 \\
\hline \multicolumn{4}{|c|}{ TOTAL PRICE OF MATERIAL } & \$ 764.46 \\
\hline \multicolumn{2}{|c|}{ MANHOURS REPAIR } & 45 HOURS & $@ \$ 40$ & $\$ 1,800$ \\
\hline \multirow{2}{*}{\multicolumn{2}{|c|}{ MANHOURS INSTALLATION }} & 6 HOUR & $@ \$ 40$ & $\$ 240.00$ \\
\hline & & & & $\$ 2,804.46$ \\
\hline \multicolumn{4}{|c|}{ HANDLING FEE $6 \%$} & \$ 168,26 \\
\hline
\end{tabular}

\section{d. Flight Schedule}

Pada pembahasan bagian ini dapat dilihat pada Lampiran 5.

\section{e. Perhitungan gain and loss}

Mengambil contoh maskapai PT.XXX yang memiliki flight schedule destinasi CGK-DPSCGK (Jakarta - Denpasar) dengan nilai revenue 2019:

Monthly Revenue US\$ 3.638.691.928, dengan seat load factor $60.78 \%$ berdasarkan data yang diperoleh dari maskapai.

Daily Revenue monthly / 30 (jika diasumsikan satu bulan 30 hari) US $\$ 3.638 .691 .928 / 30=$ US\$ 121.289.73

Daily Revenue monthly / 30

US $\$ 3,638,691.928 / 30=$ US $\$ 121289.73$

Cost for repair $=$ US $\$ 2,972.72$

45 hour $/ 24=1,875 \approx 2$ days

(daily revenue $\mathrm{x}$ days $(\mathrm{AOG}))+$ Cost for repair $=$ Loss

$(U \$ 121.289 .73 \times 2)+U S \$ 2.972,72=U S \$$ $245.552,18$

Dari perhitungan diatas diketahui maskapai PT. XXX selain kehilangan daily revenue juga memperoleh kerugian sebesar US\$ 245.552,18 (sudah ditambah cost repair).

\subsection{Perbandingan biaya}

Pada analisa ini dibuat perbandingan biaya yang harus dibayarkan tanpa pinjam (loan)

Tabel 3.3. and loss without loan.

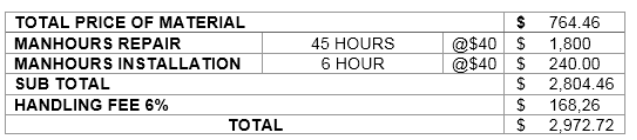

Maskapai PT. XXX mengeluarkan repair cost US\$ 2.972,72 serta kehilangan daily revenue sebesar US\$242.579,46 yang mana jika ditotal 
maskapai mengalami loss sebesar US\$ $245.552,18$.

Tabel 3.4. Cost and loss with loan.

\begin{tabular}{|c|c|c|c|c|}
\hline \multicolumn{3}{|c|}{ TOTAL PRICE OF MATERIAL } & & 764.64 \\
\hline MANHOURS REPAIR & 45 HOURS & $@ \$ 40$ & $\$$ & 1,800 \\
\hline $\begin{array}{l}\text { MANHOURS } \\
\text { INSTALL REMOVAL }\end{array}$ & 12 HOURS & $@ \$ 40$ & & 480 \\
\hline \multirow{2}{*}{\multicolumn{3}{|c|}{$\begin{array}{l}\text { SUB TOTAL } \\
\text { HANDLING FEE } 6 \%\end{array}$}} & & $3,044.64$ \\
\hline & & & & 182.67 \\
\hline LOAN PRICE & 2 DAYS & @1000 & $\$$ & 2000 \\
\hline DAILY REVENUE & ODAYS & @\$121289.73 & s & 0 \\
\hline
\end{tabular}

Sedangkan, jka maskapai PT.XXX menggunakan penawaran loan yang diberikan kepada maskapai akan mengeluarkan repair cost US\$ 3.044,64 ditambah loan cost US\$ 2.000, sehingga total biaya sebesar US\$ $5,227.31$ tanpa kehilangan daily revenue karena masih dapat terbang tanpa menunggu AOG dari perbaikan outboard aft flap tersebut.

\section{Kesimpulan}

Dari hasil analisa data perencanaan spare outboard aft flap assy pesawat B737-800NG di PT. XXX:

1. Perbaikan outboard aft flap dikarenakan disbond dalam lead time 2 hari, dan PN 113A3700-8 seharga US\$ 13.500/ea dengan lead time 4 hari. Dengan adanya pembelian spare outboard aft flap dapat menambah revenue perusahaan.

2. Nilai monthly revenue US\$ $3.638 .691,928$, yang berarti mendapatkan US\$121.289,73, jika maskapai melakukan perbaikan tanpa loan part.

\section{Daftar Pustaka}

1. UU Penerbangan No. 1 Tahun 2009. Tentang Pengertian Angkutan Udara Pasal 1 nomor 48 Undang-Undang No. 1 tahun 2009 tentang Pengertian Keselamatan Penerbangan.

2. Suwarno, FX Widadi A. 2001. Tata Operator Darat. Jakarta: Grasindo

3. Crocker, David: Dictionary of Aviation Second Edition, A\&C Black Publishers, London, 2007
4. Handoko, Singgih dan Dudi Sudibyo: AVIAPEDIA - Ensiklopedia Umum Penerbangan, PT. Kompas Media Nusantara, Jakarta, 2014.

5. The Boeing Company, Structure Manual Repair Boeing 737-800NG Rev 70, 15 Oct 2019

6. The Boeing Company, Non-destructive Test Manual Boeing 737-800NG Rev 130, 3 Dec 2019

7. The Boeing Company, Aircraft Maintenance Manual Boeing 737-800NG Rev 68, 10 Nov 2019. 